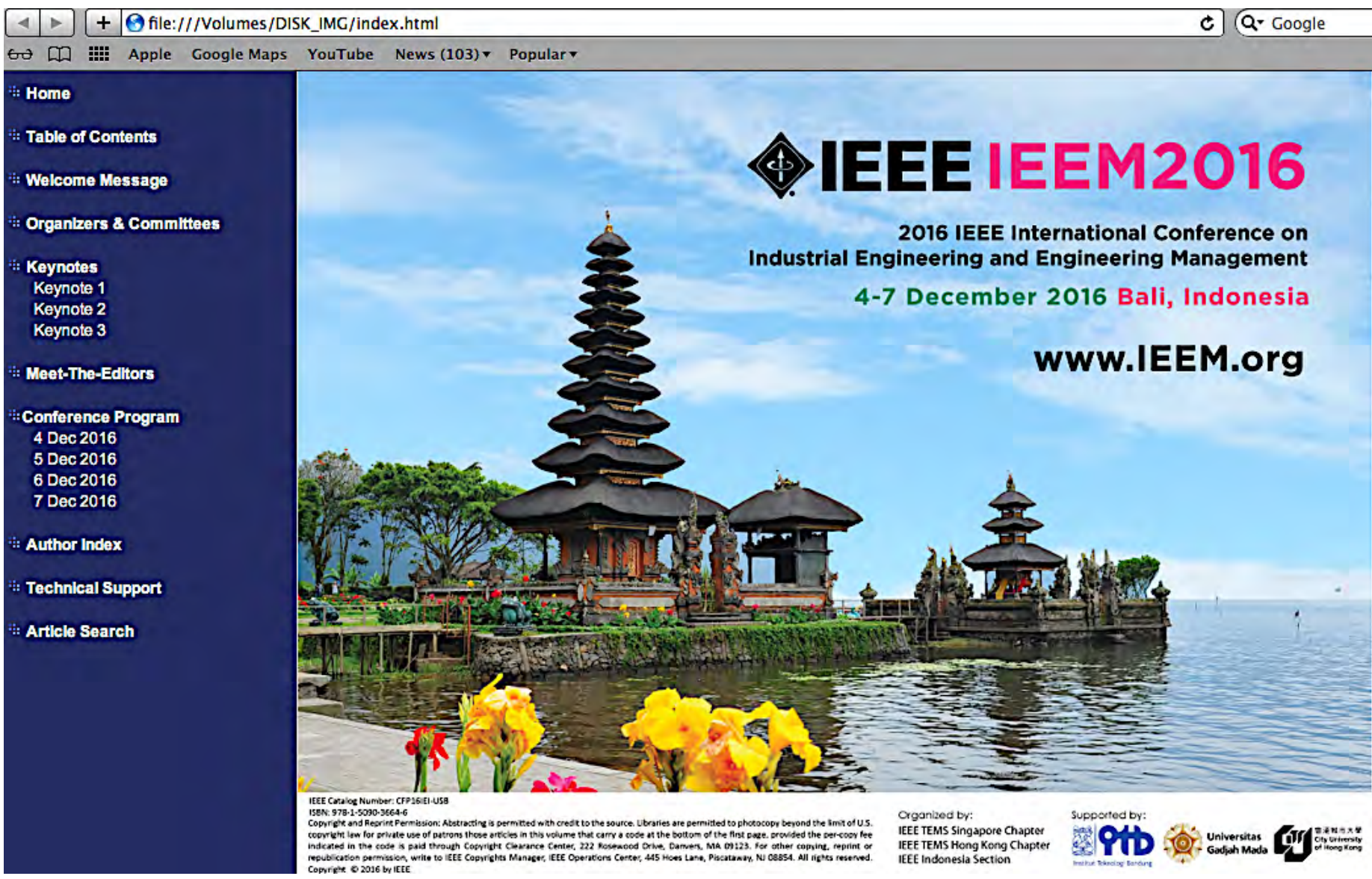

$4 \mid+1+$ file:///Volumes/DISK_IMC/index.html

c) (Q- Google

\begin{tabular}{|c|c|c|}
\hline $\begin{array}{l}\text { Home } \\
\text { Table of Contents }\end{array}$ & \multicolumn{2}{|c|}{$\begin{array}{l}\text { Proceedings of the } 2016 \mathrm{IEEE} \\
\text { International Conference on Industrial Engineering and Engineering Management }\end{array}$} \\
\hline Welcome Message & Edltors: & Contents \\
\hline Organkers \& Commlitees & $\begin{array}{l}\text { Kadarsah SURYADI } \\
\text { Institute of Technology Bandung, Indonesia }\end{array}$ & ": Welcome Message \\
\hline $\begin{array}{l}\text { Keynotes } \\
\text { Keynote } 1 \\
\text { Keynote } 2 \\
\text { Keynote 3 }\end{array}$ & $\begin{array}{l}\text { Budl HARTONO } \\
\text { Gadjah Mada University, Indonesia }\end{array}$ & $\begin{array}{l}\because: \text { Organizers and Committees } \\
\text { : Keynotes }\end{array}$ \\
\hline Meet-The-Editors & $\begin{array}{l}\text { T.M.A.ARI SAMADHI } \\
\text { Institute of Technology Bandung, Indonesia }\end{array}$ & $\begin{array}{l}\text { Keynote } 1 \text { - The Sputnik of Servgoods: Autonomous Vehicles } \\
\text { Keynote } 2 \text { - Manufacturing and Engineering Networks in a Globallsed and Data-rich World } \\
\text { Keynote } 3 \text { - Embracing the Future by Growing the Digital Ecosystem in Indonesia and Deliver Value to Customers }\end{array}$ \\
\hline $\begin{array}{l}\text { Conference Program } \\
4 \text { Dec } 2016\end{array}$ & $\begin{array}{l}\text { Nan CHEN } \\
\text { National University of Singapore, Singapore }\end{array}$ & ": Meet-The-Editors \\
\hline $\begin{array}{l}5 \text { Dec } 2016 \\
6 \text { Dec } 2016 \\
7 \text { Dec } 2016\end{array}$ & $\begin{array}{l}\text { MIn XIE } \\
\text { City University of Hong Kong, Hong Kong SAR }\end{array}$ & $\begin{array}{l}\because \text { Conference Program } \\
\text {. 4Dec } 2016 \text { (Sun) }\end{array}$ \\
\hline Author Index & $\begin{array}{l}\text { IEEE Catalog Number: CFP16IEI-USB } \\
\text { ISBN: } 978-1-5090-3664-6\end{array}$ & $\begin{array}{l}5 \text { Dec } 2016 \text { (Mon) } \\
\text { : } 6 \text { Dec } 2016 \text { (Tue) } \\
7 \text { Dec } 2016 \text { (Wed) }\end{array}$ \\
\hline Technical Support & Technical Support: & ": Author Index \\
\hline Artlcle Search & 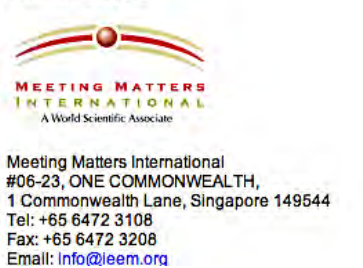 & $\begin{aligned} & A-F \\
&: G-L \\
&: M-R \\
&: S-Z\end{aligned}$ \\
\hline
\end{tabular}




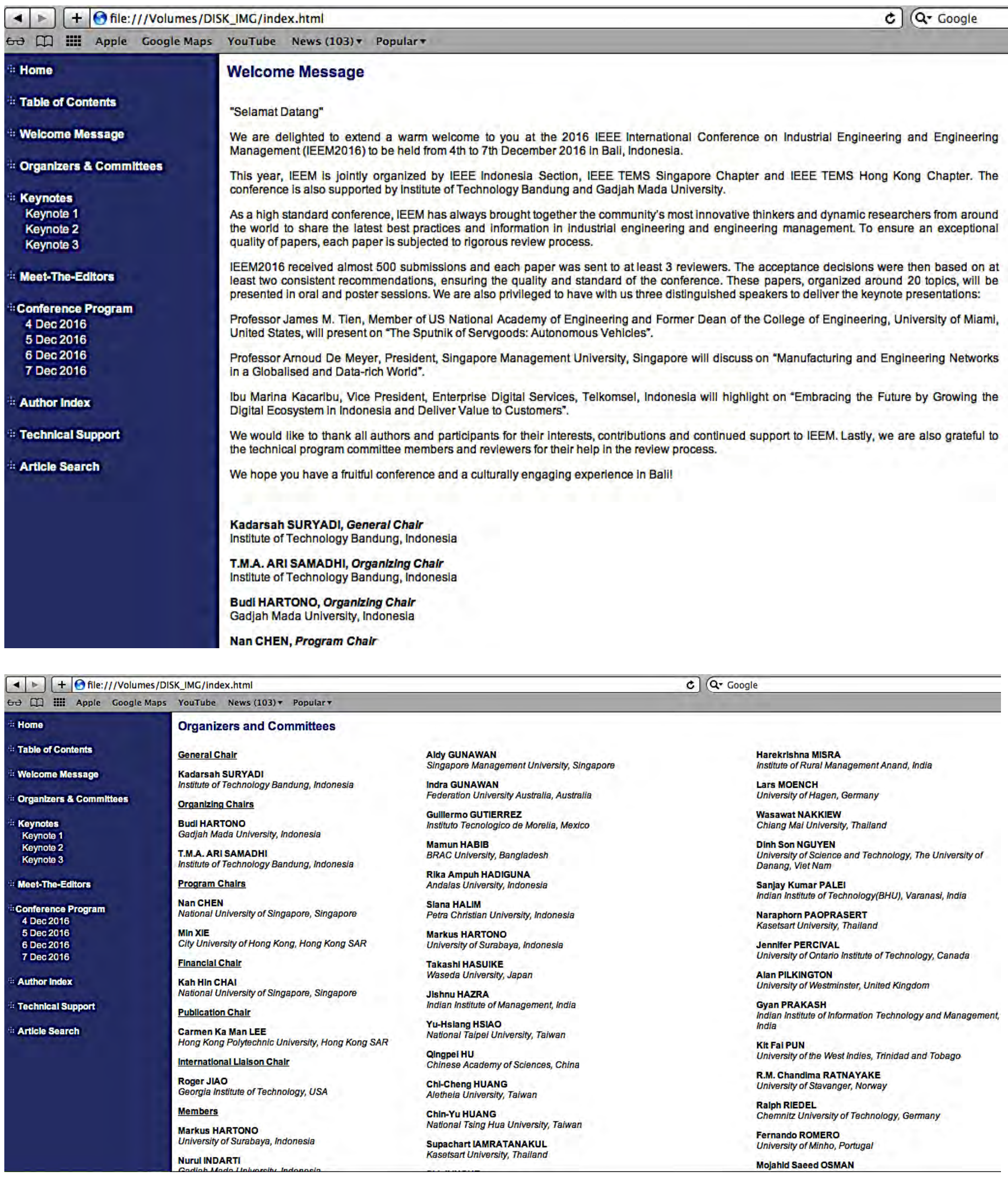




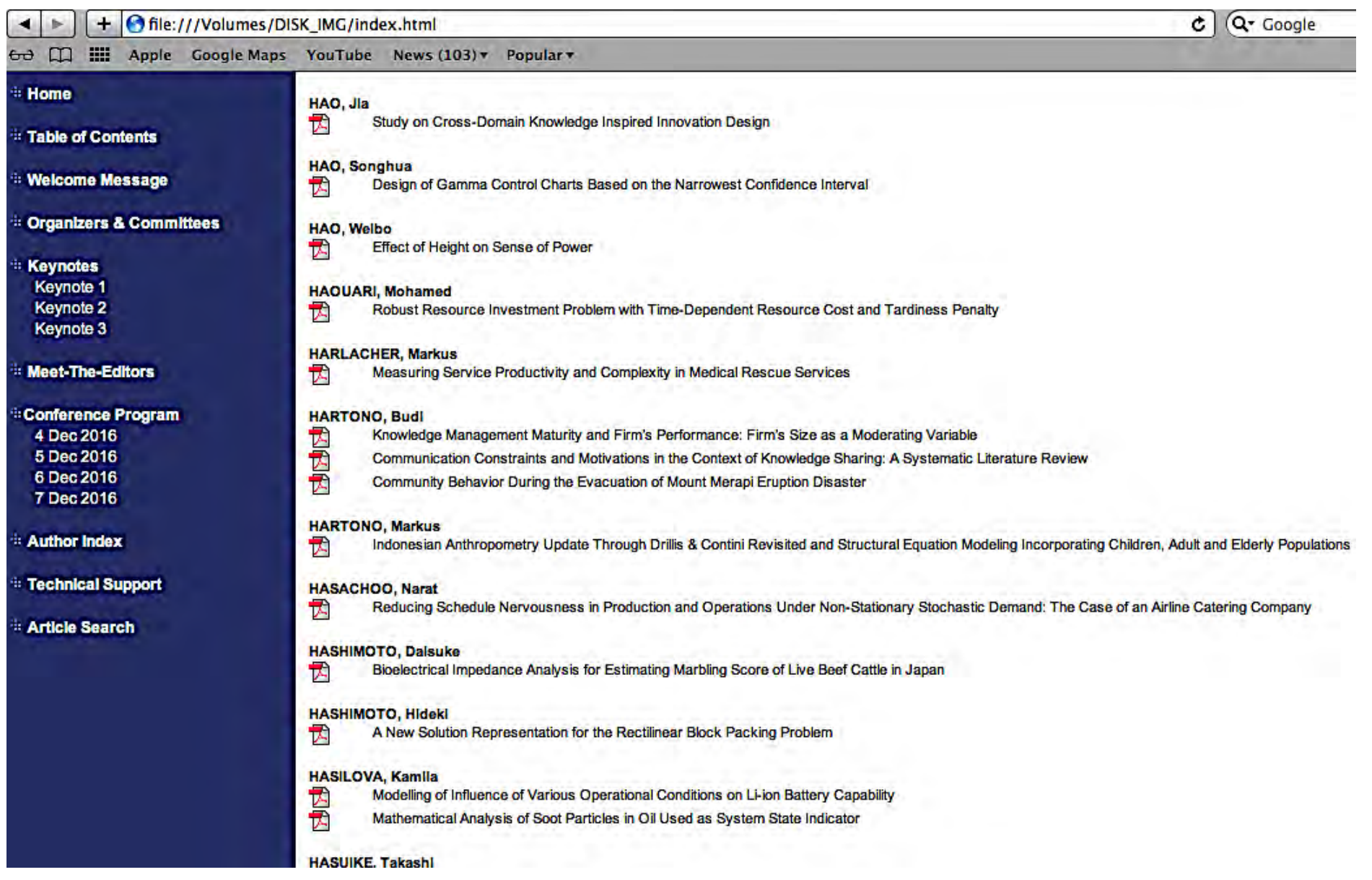




\title{
Indonesian Anthropometry Update Through Drillis \& Contini Revisited and Structural Equation Modeling Incorporating Children, Adult and Elderly Populations
}

\author{
M. Hartono ${ }^{1}$ \\ ${ }^{1}$ Department of Industrial Engineering, University of Surabaya, Surabaya, Indonesia \\ (markus@staff.ubaya.ac.id)
}

\begin{abstract}
Research on anthropometry deals with human physical measurement, capability and limitation. Due to various body measures of user of different cultures, gender, and geographical factors, then an understanding of anthropometry characteristics is a must. This study adopts Drillis and Contini ratio scaling method and complements the previous research by incorporating Indonesian adults [150 subjects], children [200 subjects] and elderly [120 subjects] groups. By employing Structural Equation Modeling (SEM), it was shown that limb and girth \& width segments were significantly correlated with stature and weight, respectively to all population groups, both for male and female subjects. Moreover, it was confirmed that the ratio scale method has been sufficiently applied to all anthropometric groups, so that the body segments measures can be predicted. Practically, the finding can be utilized to support product design and development phases, especially in the use of more appropriate anthropometric data.

Keywords - Indonesian Anthropometry, Structural Equation Modeling, Drillis and Contini, Ratio Scaling
\end{abstract}

\section{INTRODUCTION}

Anthropometry is a basic principle and discipline in Ergonomics/Human Factors Engineering. It is known as a technique to measure, collect, and analyze human body dimensions [1]. All collected measures will be used for any physical product designs and development taking into account human physical capability and limitation.

According to Tan et al. [2], the findings of anthropometry may vary from sample-to-sample to country-to-country based, including population groups. The way to collect anthropometric data may vary as well, from a very simple one yet acceptable (see [2]) to the most sophisticated procedures (see [3]). It seems to be simple study; however, its contribution will be of highly demanding, both theoretically and practically.

Anthropometry shows its superiority as a basic ergonomics. Any product or system design which involves human as a central role, anthropometry is required. As a consequence, lack of it will lead to system discrepancy and malfunction, such as discomfort, user dissatisfaction, as well as potential injuries and musculoskeletal disorders (MSDs).

Research on anthropometry has been conducted extensively in many sectors across countries. In Indonesia, especially, there are two significant publication of Indonesia anthropometry in ergonomics-related international journals (please refer to [2] and [4]). Due to large and various number of populations and ethnic groups, there is a need to consistently and continuously update the anthropometric data. Apart from common method with a standard form in collecting anthropometric data, sometimes the problem is occurred due to the compilation process of collected data and to publish it online. Nevertheless, a new initiative of how to publish anthropometric data has been promoted (see www.antropometriindonesia.org). Currently, there are more than 1,000 anthropometric data collected. However, more effort to update it is still of urgent.

This study, essentially, concerns on how to collect anthropometric data more effective and efficient, surely, without sacrificing the quality of data. In other words, while constantly compiling the anthropometric data, the experimenter needs to maintain its validity and reliability. The question is raised. Among all body measures, given very limited time and subjects, which one is the most critical? By revisiting Drillis and Contini [5] and Peacock et al. [6], it is highlighted that human body measures can be predicted by a single measure of stature and body weight. More specifically, width and girth measures are deemed to be correlated with body weight, whereas limb measures are connected with stature.

However, what body measures are prioritized and ranked according to their relationships with body stature and weight is still relatively unexplored. Moreover, how confident it is judged that body stature and weight are deemed as sufficient predictor, is of interesting. Another thing to consider is that how different population groups (e.g., children, adult, and elderly) give various results on body scale. In other words, for instance, the proportion between body measures and stature across population groups may be diversified. Thus, this study was carried out.

The objective of this study is that, (i) to revisit the findings of previous studies $[1 ; 5 ; 6]$, by doing analysis on the correlations among many measures from data obtained in recent anthropometric study of Indonesian children, adult, and elderly groups using Structural Equation Modeling (SEM), and (ii) to provide Body Mass Index (BMI) as the application of the compiled anthropometric data and accompanied by ratio scale. It is expected that the results of this study will be utilized a set of guide to predict reliable anthropometric measures, and to better understand the characteristics of anthropometry across three different population groups.

\section{METHODOLOGY}

This research applied convenience sampling in collecting Indonesian anthropometric data, involving three population groups, i.e., children (ranged from 7 - 12 
years old), adult (ranged from 18 - 25 years old, mostly taken from university students), and elderly (ranged from 55 - 70 years old). In total, there were 470 subjects taken, consisting of 200 children (100 males; 100 female), 150 adults (75 males; 75 females), and 120 elderly (65 males; 55 females).

According to Tan et al. [2], there were 36 body dimensions used. It starts from stature, eye height, to forward grip reach. During the data collection process, there were two experimenters involved for each population group. They supported to do setup, adjustment and recording the 36 measures. The names of 36 body dimensions are provided in the Appendix.

Towards the anthropometric data measurement, there were two stages conducted. Firstly, all subjects have been informed and confirmed whether they were willing to be a subject. With respect with privacy and sensitive issues, there is no obligation in case the subjects reject the offer. Secondly, referring to Tan et al. [2], a portable convenient anthropometric device, a body map and meter tapes were used. With a minimum target of 100 samples with a balanced group of female and male subjects, a pilot run of 5 subjects for each population groups (i.e., 5 children, 5 adults, and 5 elderly) has been carried out. Completion time, appropriateness of posture, the exact point of bony tips, appropriateness of instrument used, and some potential misunderstandings related to privacy issues were addressed and confirmed. Since it is of being sensitive measurement due to human body related, especially in Indonesia, an appropriate measurement rule was applied. It was implemented that a male experimenter measured the male subjects, while a female experimenter handled the female subjects. Since there were 2 experimenters for each population group, thus, 1 experimenter handled the measurement, and the other one took note or recorded the data. According to the pilot test, it took about 20 minutes to finish the measurement for each subject.

All data collected were compiled, screened out, and tested. Unwanted data were removed due to high variance. This was to test and control the validity and reliability. Statistic descriptive, Drillis and Contini's ratio scale method and path analysis using SEM (Structural Equation Modeling) have been done and provided in Tables I-II and Figures 1-3.

\section{RESULTS AND DISCUSSION}

This part provides the statistic descriptive of basic measures, Structural Equation Modeling (SEM) to extract significant multiple predictor variables and prediction analysis, and ratio scaling to predict measures using body stature and weight, respectively (see Table I, Table II, Table III, Figure 1 and Figure 2 for details).

Referring to Table I, according to BMI, it is shown that both samples (male and female) were located at the healthy weight zone (with BMI range of 18.5 and 23, as available at http://cchrchealth.org/health-calculators/bodymass-index-bmi-adults). A more critical result is that at the female elderly group, in which it has BMI 23.35, which is a bit above the maximum limit of 23. However, it is still acceptable as a healthy category.

TABLE I

STATISTIC DESCRIPTIVE OF BASIC ANTHROPOMETRY MEASURES

\begin{tabular}{|c|c|l|l|l|l|l|l|l|l|l|}
\hline \multirow{2}{*}{ Gender } & \multicolumn{9}{|c|}{ Stature (in cm) } & \multicolumn{5}{c|}{ Weight (in kg) } & \multirow{2}{*}{ BMI } \\
\cline { 2 - 8 } & Mean & SD & Max & Min & Mean & SD & Max & Min & \\
\hline \multicolumn{8}{|c|}{ Adren } \\
\hline Male & 132.6 & 6.1 & 157.6 & 128.3 & 32.9 & 10.9 & 45 & 28 & 18.71 \\
\hline Female & 131.9 & 4.5 & 152.3 & 125.3 & 32.1 & 6.8 & 43.4 & 26 & 18.45 \\
\hline \multicolumn{8}{|c|}{ Adult } \\
\hline Male & 172.5 & 6.3 & 193 & 158 & 67.8 & 12.3 & 112 & 42 & 22.79 \\
\hline Female & 158.4 & 5.7 & 173.5 & 145.2 & 51.2 & 7.3 & 67 & 37.5 & 20.41 \\
\hline \multicolumn{10}{|c|}{ Elderly } \\
\hline Male & 162.6 & 6.3 & 189.5 & 154.3 & 58.8 & 12 & 103 & 60 & 22.24 \\
\hline Female & 145.3 & 6.8 & 174 & 140.6 & 49.3 & 8.2 & 67.5 & 39 & 23.35 \\
\hline
\end{tabular}

There are two general models proposed, (i) limb body segments $\rightarrow$ stature $\rightarrow$ BMI, and (ii) girth \& width segments $\rightarrow$ weight $\rightarrow$ BMI. According to findings by Peacock et al. [6], incorporating three this study formulized four hypotheses, as follows:

$\mathrm{H} 1$ : Limb segment is positively related to stature to all three population groups

H2: Girth \& width segment is positively related to body weight to all three population groups

H3: Stature is positively related to BMI

H4: Body weight is positively related to BMI

By using SEM path-coefficient, it was built two significant models as shown in Figures 1, 2 and 3, for each population group. These were six models (i.e., A, B, C, D, E and F) after several iterative modified models. Validity and reliability tests have been conducted. SmartPartial Least Square (Smart-PLS) 2.0 M3 [7] was utilized. PLS was used since it makes few demands on any distributional form of measured variables and deals with small sample sizes [8]. Three construct validity and reliability tests were reported, i.e., convergent validity, discriminant validity, and reliability. In terms of convergent validity, there are three criteria used [11], which are (i) all item factor loadings should exceed 0.7 , (ii) construct reliabilities should exceed 0.7 , and average variance extracted (AVE) of construct should exceed 0.5. Discriminant validity is based on the square root of AVE for a particular construct must be greater than its corresponding inter-construct correlation coefficient. A minimum Cronbach's alpha of 0.6 is deemed to be acceptable value of reliability [11]. The results of validity and reliability test were shown in Table II. All constructs were deemed valid and reliable for all population groups.

TABLE II

MEASUREMENT OF CONSTRUCTS

\begin{tabular}{|c|c|c|c|c|c|c|c|c|c|}
\hline \multirow[b]{2}{*}{ Construct } & \multicolumn{3}{|c|}{ Children } & \multicolumn{3}{|c|}{ Adult } & \multicolumn{3}{|c|}{ Elderly } \\
\hline & AVE* & \begin{tabular}{|c|} 
Composite \\
reliability
\end{tabular} & $\begin{array}{c}\text { Cronbach } \\
\text { alpha }\end{array}$ & $\mathrm{AVE}^{*}$ & $\begin{array}{c}\text { Composite } \\
\text { reliability }\end{array}$ & $\begin{array}{c}\text { Cronbach } \\
\text { alpha }\end{array}$ & AVE* $^{*}$ & \begin{tabular}{|c|} 
Composite \\
reliability
\end{tabular} & $\begin{array}{c}\text { Cronbach } \\
\text { alpha }\end{array}$ \\
\hline Limb segment & 0.496 & 0.911 & 0.871 & 0.494 & 0.936 & 0.924 & 0.483 & 0.938 & 0.915 \\
\hline \begin{tabular}{|l|l} 
Stature \\
\end{tabular} & 0.511 & 0.924 & 0.921 & 0.497 & 0.925 & 0.914 & 0.496 & 0.943 & 0.921 \\
\hline Width \& girth segment & 0.487 & 0.937 & 0.878 & 0.511 & 0.915 & 0.907 & 0.509 & 0.972 & 0.913 \\
\hline Weight & 0.524 & 0.971 & 0.968 & 0.481 & 0.874 & 0.856 & 0.473 & 0.861 & 0.843 \\
\hline
\end{tabular}

According to path analysis, it shows that, for adult group, at Model A (i.e., male sample), the stature was highly correlated (with factor loading of 0.891 ) with body 
measure 3 (i.e., shoulder height), while the body weight was closely correlated (0.896) with body measure 21 (i.e., abdominal depth). At the Model B (i.e., female sample), they were dimension 2 (i.e., eye height) and dimension 12 (i.e., thigh thickness) were deemed highly correlated (with factor loadings of 0.931 and 0.852 , respectively) with stature and body weight, respectively. All constructs (i.e., stature and weight) were highly fitted with their respective predictors (limb segments, and width \& girth segments), which were shown by high value of $\mathrm{R}^{2}$ (i.e., more than 0.5). Similar to adult group, the remaining groups (children and elderly) had the same pattern. All constructs were significantly correlated with their predictors. More specifically, at Model C (i.e., male sample), the stature was highly correlated with body measure 4 (i.e., elbow height), whereas the body weight was correlated with body measure 12 (i.e., thigh thickness). Still, at the same group, referring to Model D (i.e., female sample), the stature was highly correlated with body measure 3 (i.e., shoulder height), whereas the body weight was correlated with body measure 12 (i.e., thigh thickness). The last group, which is provided in Model E and F for elderly group, shows relative results. At Model E (i.e., male sample), the stature was highly correlated with body measure 3 (i.e., shoulder height), whereas the body weight was correlated with body measure 20 (i.e., abdominal depth). While, at Model F (i.e., female sample), similar to that Model D, the stature was highly correlated with body measure 3 (i.e., elbow height), whereas the body weight was correlated with body measure 12 (i.e., thigh thickness).

As shown in Table III, that was clearly shown that limb segment was highly significantly correlated with stature, applies to all population groups. In addition, width \& girth segment and body weight were highly significant, to all population groups as well. Surely, it gives more confident that Drillis and Contini method [5] and findings by Peacock et al.[6] have been confirmed. Stature is deemed to be a good predictor to limb segments, and body weight will be of good predictor to width \& girth segments. More interestingly, all population groups show relatively the similar patterns. Thus, with a range of 7 to 70 years old, the growth of human body measures related to stature and body weight was relatively of the same pattern.

Body mass index (BMI) is a representative equivalent measure of body fatness independent of age, race, gender, sexual maturation, and distribution of fat in children and adolescents [10]. BMI was significantly and positively correlated with age, stage of maturation, and all of the anthropometric variables in each race-sex group such as the waist and hip ratio.

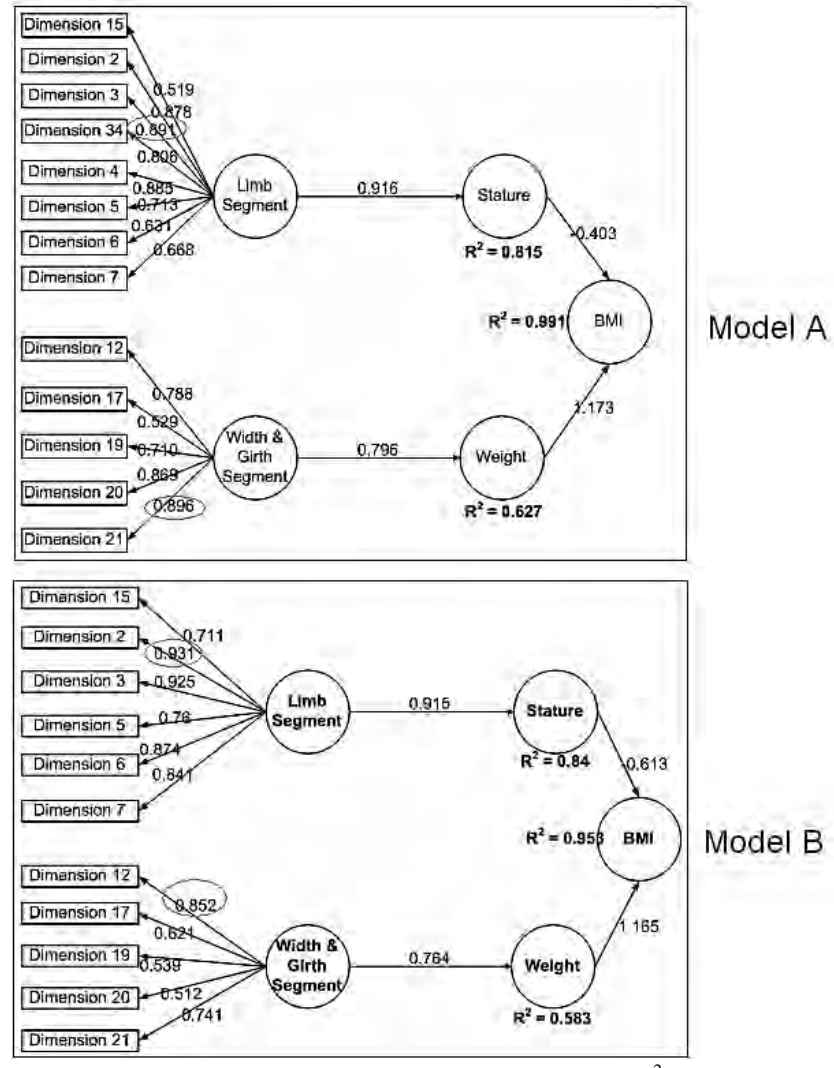

Fig.1. A structural model with path coefficients and $\mathrm{R}^{2}$ for male (Model A) and female (Model B) for adult group

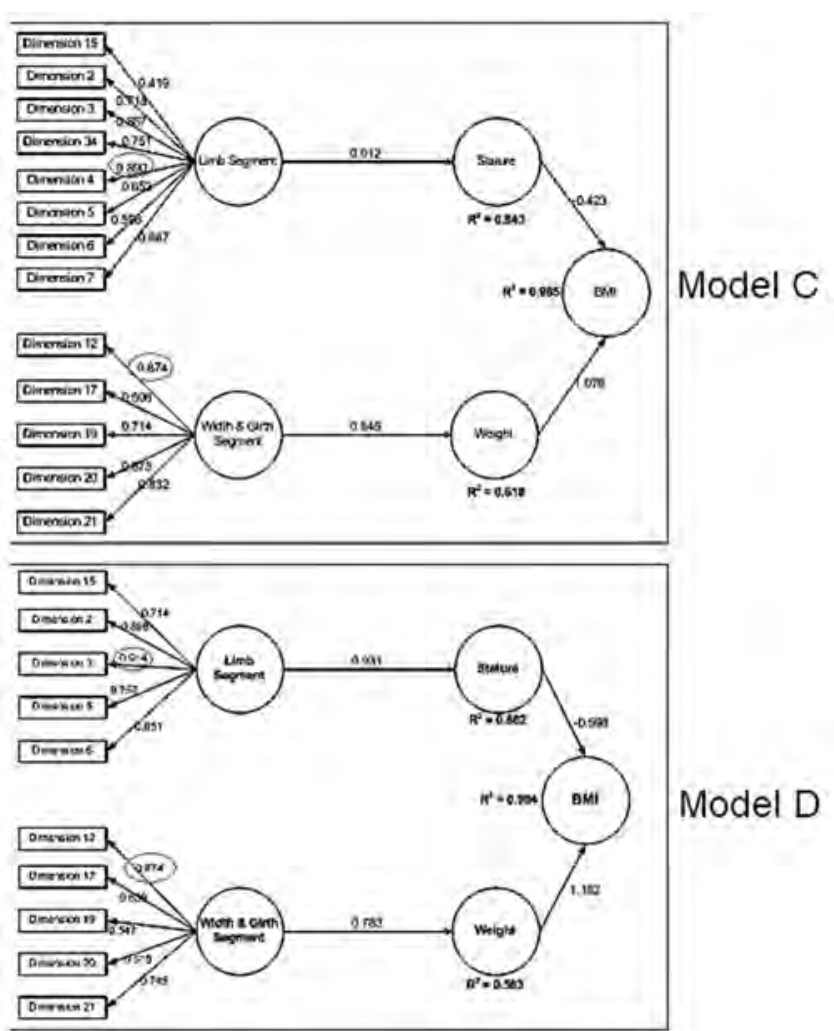

Fig.2. A structural model with path coefficients and $\mathrm{R}^{2}$ for male (Model C) and female (Model D) for children group 

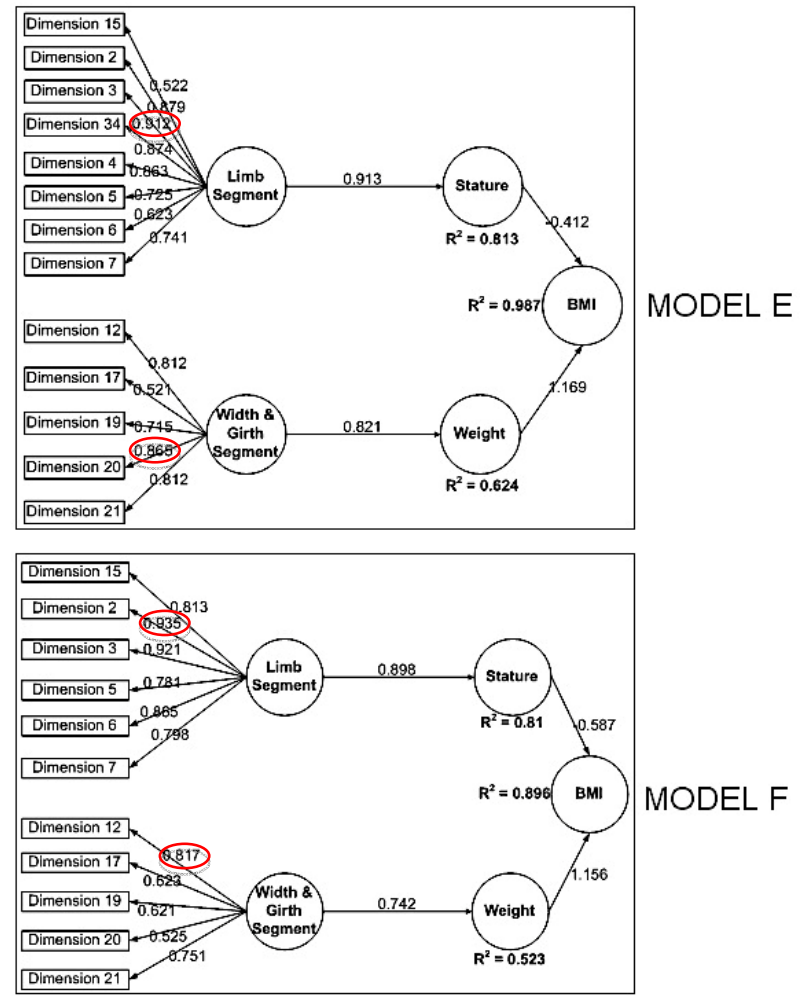

Fig.3. A structural model with path coefficients and $\mathrm{R}^{2}$ for male (Model E) and female (Model F) for elderly group

TABLE III

SIGNIFICANT VALUE OF PATH MODEL

\begin{tabular}{|l|c|c|c|c|c|c|}
\hline \multirow{2}{*}{ Path } & \multicolumn{7}{|c|}{ MALE } & \multicolumn{3}{c|}{ FEMALE } \\
\cline { 2 - 8 } & Coeff. & SE* $^{*}$ & $\mathrm{t}_{\text {value }}$ & Coeff. & SE* $^{*}$ & $\mathrm{t}_{\text {value }}$ \\
\hline $\begin{array}{l}\text { Limb segment } \rightarrow \\
\text { Stature }\end{array}$ & 0.912 & 0.018 & 50.67 & 0.931 & 0.014 & 66.50 \\
\hline Stature $\rightarrow$ BMI & -0.423 & 0.046 & 9.20 & -0.598 & 0.058 & 10.31 \\
\hline Weight $\rightarrow$ BMI & 1.076 & 0.050 & 21.52 & 1.152 & 0.054 & 21.33 \\
\hline $\begin{array}{l}\text { Width \& girth } \\
\text { segment } \rightarrow \text { Weight }\end{array}$ & 0.845 & 0.036 & 23.47 & 0.783 & 0.029 & 27.00 \\
\hline & 0.916 & 0.019 & 48.21 & 0.915 & 0.011 & 83.18 \\
\hline $\begin{array}{l}\text { Limb segment } \rightarrow \\
\text { Stature }\end{array}$ & -0.403 & 0.051 & 7.90 & -0.613 & 0.056 & 10.95 \\
\hline Stature $\rightarrow$ BMI & 1.173 & 0.036 & 32.58 & 1.165 & 0.052 & 22.40 \\
\hline Weight $\rightarrow$ BMI & 0.796 & 0.038 & 20.95 & 0.764 & 0.038 & 20.11 \\
\hline $\begin{array}{l}\text { Width \& girth } \\
\text { segment } \rightarrow \text { Weight }\end{array}$ & 0.913 & 0.016 & 57.06 & 0.898 & 0.034 & 26.41 \\
\hline & -0.412 & 0.051 & 8.08 & -0.587 & 0.037 & 15.86 \\
\hline $\begin{array}{l}\text { Limb segment } \rightarrow \\
\text { Stature }\end{array}$ & 1.169 & 0.041 & 28.51 & 1.156 & 0.062 & 18.65 \\
\hline Stature $\rightarrow$ BMI & 0.821 & 0.039 & 21.05 & 0.742 & 0.039 & 19.03 \\
\hline Weight $\rightarrow$ BMI & $\begin{array}{l}\text { Width \& girth } \\
\text { segment } \rightarrow \text { Weight }\end{array}$ & \multicolumn{7}{|c|}{ Adderly } \\
\hline
\end{tabular}

BMI is chosen to be one of applied uses of anthropometric data. The critical points are that which limb segments are highly correlated with stature, and which girth \& width segments are highly correlated with body weight. More specifically, this study aimed to find out, across different population groups, which body segments are in common. BMI is proposed to be indirectly correlated with limb segments, and girth \& width segments. Thus, more specifically, due to limited number of body segments or anthropometric measures with either no data of stature or body weight, it is possible to predict BMI. It is the detailed shape of anthropometry.

It was found that limb segments were correlated with stature, and also girth \& width segments were deemed closely correlated with body weight. This study confirmed the previous findings by Peacock et al. [6]. More specifically, across different groups, the segments of eye height, shoulder height, hip height, knuckle height, and knee height were commonly highly correlated with stature. While, the segments of thigh thickness, shoulder breadth, hip breadth, chest depth and abdominal depth were commonly highly correlated with body weight. Hence, those all significant body segments were deemed good predictor for BMI, given either with or without information of body stature and weight, or vice versa.

More critically, this study confirms the finding of the previous study [9], which highlights that the scaling method cannot be applied 6 years of age due to too large discrepancy between skull height and thickness. Perhaps, it may be applied to 70 years and above. More ages, there will be a decrease of human muscle-ability, flexibility, and metabolism that may be affecting the body dimensions.

In the future study, it is highly recommended to explore and define more appropriate dependent variable for anthropometric data measurement, which is of more beneficial and applicable to the market.

\section{CONCLUSION AND FURTHER RESEARCH}

Study on anthropometry in a certain nationality by incorporating all population groups (i.e., children, adult, and elderly) may provide a new perspective of how the anthropometric characteristics may vary. So far, much research on anthropometry has evaluated and analyzed the body characteristics of adult population. This current study complement the understanding of anthropometric characteristics, especially the linear relationship between limb segments and width/girth segments, and its prediction model using Drillis and Contini's ratio scale.

According to the research finding, in all population groups (i.e., children, adult, and elderly), limb segments have significant correlation with stature, whereas width and girth segments have significant one with body weight. Again, confidently, body weight and stature can be used as a predictor of body mass index (BMI).

Given more valid measurement and procedures and sufficient sample size, the human body dimensions can be predicted in the near future by proposing mathematical modeling. Structural Equation Modeling is found to be a powerful tool to present the correlations among anthropometric dimensions.

This study confirms the findings that body weight was found to be a predictor of width and girth measures, whereas stature was found to be highly correlated with limb lengths. More specifically, this study provides more insight about which body segments can be predicted more precisely through either stature or body weight, according to statistical testing. Practically, the findings can be 
applied to any product or system design taking into account anthropometric measures, to all population groups (i.e., children, adult and elderly).

The most challenging part in documenting anthropometric data in general is that how to measure, collect and compile anthropometric data effectively and efficiently. Effective aspect covers how to get the right subject, body segment, and measurement process. Efficient aspect includes how to get a targeted number of anthropometric data subjected to time or subject group constraints. This research tried to address the issue of limited number anthropometric data for certain population group (clustered according to different ages) in Indonesia. Given a sufficient sample size, a structural model was proposed, and validated. Several body limb segments were found to be significantly correlated with stature, so did the girth and body width with the body weight. Through ratio scaling method, as proposed by Drillis \& Contini [5; 6], this study found that several body segments can be predicted. Hence, it is hoped to attain more effective and efficient anthropometric data due to the subjects measured constraint.

Even though the statistical results show good fit of model, this study can be extended and enhanced by incorporating more sample size and diversification. For instance, since Indonesia is of a various ethnic-based country, more samples from special populations such as elderly and children might be of interest.

\section{ACKNOWLEDGEMENT}

This research is financially supported by the Department of Industrial Engineering, University of Surabaya (Ubaya) and Indonesian Directorate General of Higher Education (DIKTI). Essentially, this study is a part of Indonesian anthropometry research granted by Competitive Grant "Hibah Bersaing Desentralisasi" DIKTI year 2016.

\section{REFERENCES}

[1] S. Pheasant, and C.M. Haslegrave, Body Space: Anthropometry, Ergonomics, and the Design of Work. Third ed. New York: Taylor \&Francis Inc, 2006.

[2] K.C. Tan, M. Hartono, and N. Kumar, "Anthropometry of the Singaporean and Indonesian Populations," International Journal of Industrial Ergonomics, vol. 40, no. 6, pp. 757766, Nov. 2010.

[3] J. Park, Y. Nam, E. Lee, andS. Park, "Error detection in three-dimensional surface anthropometric data, "International Journal of Industrial Ergonomics, vol. 39, no. 1, pp. 277-282.

[4] A. Widyanti, L. Susanti, I.Z. Sutalaksana, andK. Muslim, "Ethnic differences in Indonesian anthropometry data: Evidence from three different largest ethnics," International Journal of Industrial Ergonomics, vol. 47, 72-78.

[5] R. Drillis and R. Contini, R. Body segment parameters. DHEW 1166-03. New York University, School of Engineering and Science, New York, 1966.
[6] J.B. Peacock, M. Aravindakshan, T. Xin, C.Y. Ping, L.W. Ping, F. Ding, K.C. Tan, M. Hartono, and N.Y. Stella, "Drillis and Contini Revisited," in Advances in Usability Evaluation, Eds. Rebelo F. and M.M. Soares, Boca Raton: CRC Press, 2012.

[7] C.M. Ringle, S. Wende, and A. Will, Smart PLS. University of Hamburg, Hamburg, Germany, 2005.

[8] W.W. Chin, "The partial least squares approach to structural equation modeling," in Modern Methods for Business Research, G.A. Marcoulides, Ed. Mahwah, NJ: Erlbum,1998,pp.295-336.

[9] V.R. Preedy, "Handbook of Anthropometry: Physical Measures of Human Form in Health and Disease”, Vol. 1, Parts 1-6, Verlag New York: Springer, 2012.

[10] S.R. Daniels, P.R. Khoury, and J.A. Morrison, "The Utility of Body Mass Index as a Measure of Body Fatness in Children and Adolescents: Differences by Race and Gender”, Vol. 99, No. 6, 1997.

[11] J. C., Nunnally, J.C., "Psychometric Theory", 2nd ed., McGraw-Hill, New York, 1978.

\section{APPENDIX}

List of body dimension [1; 2]

$\begin{array}{llll}\mathbf{1} & \text { Stature } & \mathbf{1 9} & \text { Hip breadth } \\ \mathbf{2} & \text { Eye height } & \mathbf{2 0} & \text { Chest (bust) depth } \\ \mathbf{3} & \text { Shoulder height } & \mathbf{2 1} & \text { Abdominal depth } \\ \mathbf{4} & \text { Elbow height } & \mathbf{2 2} & \text { Shoulder-elbow length } \\ \mathbf{5} & \text { Hip height } & \mathbf{2 3} & \text { Elbow-fingertip length } \\ \mathbf{6} & \text { Knuckle height } & \mathbf{2 4} & \text { Upper limb length } \\ \mathbf{7} & \text { Fingertip height } & \mathbf{2 5} & \text { Shoulder-grip length } \\ \mathbf{8} & \text { Sitting height } & \mathbf{2 6} & \text { Head length } \\ \mathbf{9} & \text { Sitting eye height } & \mathbf{2 7} & \text { Head breadth } \\ \mathbf{1 0} & \text { Sitting shoulder height } & \mathbf{2 8} & \text { Hand length } \\ \mathbf{1 1} & \text { Sitting elbow height } & \mathbf{2 9} & \text { Hand breadth } \\ \mathbf{1 2} & \text { Thigh thickness } & \mathbf{3 0} & \text { Foot length } \\ \mathbf{1 3} & \text { Buttock-knee length } & \mathbf{3 1} & \text { Foot breadth } \\ \mathbf{1 4} & \text { Buttock-popliteal length } & \mathbf{3 2} & \text { Span } \\ \mathbf{1 5} & \text { Knee height } & \mathbf{3 3} & \text { Elbow span } \\ \mathbf{1 6} & \text { Popliteal height } & \mathbf{3 4} & \text { Vertical grip reach } \\ \mathbf{1 7} & \text { Shoulder breadth (bideltoid) } & \mathbf{3 5} & \text { Vertical grip reach (sitting) } \\ \mathbf{1 8} & \text { Shoulder breadth } & \mathbf{3 6} & \text { Forward grip reach } \\ & \text { (biacromial) } & & \end{array}$

